\title{
Mosquito Mycobiota: An Overview of Non-Entomopathogenic Fungal Interactions
}

\author{
Simon Malassigné, Claire Valiente Moro and Patricia Luis * \\ Univ Lyon, Université Claude Bernard Lyon 1, CNRS, INRAE, VetAgro Sup, UMR Ecologie Microbienne, F-69622 \\ Villeurbanne, France; simon.malassigne@etu.univ-lyon1.fr (S.M.); claire.valiente-moro@univ-lyon1.fr (C.V.M.) \\ * Correspondence: patricia.luis@univ-lyon1.fr
}

Received: 23 June 2020; Accepted: 10 July 2020; Published: 12 July 2020

\begin{abstract}
The growing expansion of mosquito vectors leads to the emergence of vector-borne diseases in new geographic areas and causes major public health concerns. In the absence of effective preventive treatments against most pathogens transmitted, vector control remains one of the most suitable strategies to prevent mosquito-borne diseases. Insecticide overuse raises mosquito resistance and deleterious impacts on the environment and non-target species. Growing knowledge of mosquito biology has allowed the development of alternative control methods. Following the concept of holobiont, mosquito-microbiota interactions play an important role in mosquito biology. Associated microbiota is known to influence many aspects of mosquito biology such as development, survival, immunity or even vector competence. Mosquito-associated microbiota is composed of bacteria, fungi, protists, viruses and nematodes. While an increasing number of studies have focused on bacteria, other microbial partners like fungi have been largely neglected despite their huge diversity. A better knowledge of mosquito-mycobiota interactions offers new opportunities to develop innovative mosquito control strategies. Here, we review the recent advances concerning the impact of mosquito-associated fungi, and particularly nonpathogenic fungi, on life-history traits (development, survival, reproduction), vector competence and behavior of mosquitoes by focusing on Culex, Aedes and Anopheles species.
\end{abstract}

Keywords: mosquito-microbiota interactions; mycobiota; Aedes-Anopheles-Culex spp

\section{Introduction}

Mosquitoes are insects belonging to the order Diptera. They form the family Culicidae, which comprise more than 3500 species distributed among 41 different orders [1]. Most species are hematophagous as blood meal is necessary for egg production. Adult females usually feed on vertebrate hosts and use digestive enzymes secreted from their midgut epithelial cells to degrade blood proteins into amino acids required for egg production [2]. Such blood meals can also result in pathogen transmission to humans and other animals. Indeed, when a female mosquito bites an infected host, pathogens are taken together with the blood into the mosquito midgut. After being sucked up in blood, pathogens infect the gut epithelial cells, enter the hemolymph, invade the salivary glands, and the mosquito can then transmit the pathogen while biting a healthy host. [3]. The most important mosquito-borne diseases are transmitted by three mosquito genera (Anopheles, Aedes, and Culex). If Anopheles mosquitoes spread malaria parasites (Plasmodium spp.) and O'nyong-nyong virus, Culex species are major vectors of filarial nematodes and West Nile virus (Figure 1). In addition to nematodes (Dirofilaria spp.), Aedes mosquitoes transmit several arboviruses, including dengue, chikungunya, West Nile, Zika, and yellow fever viruses [3]. 


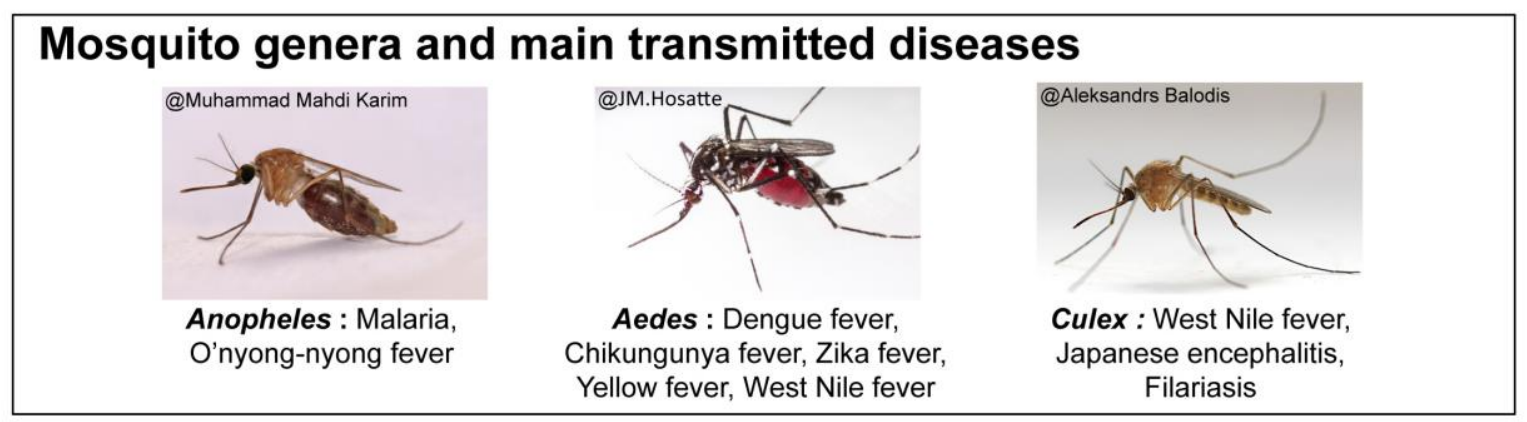

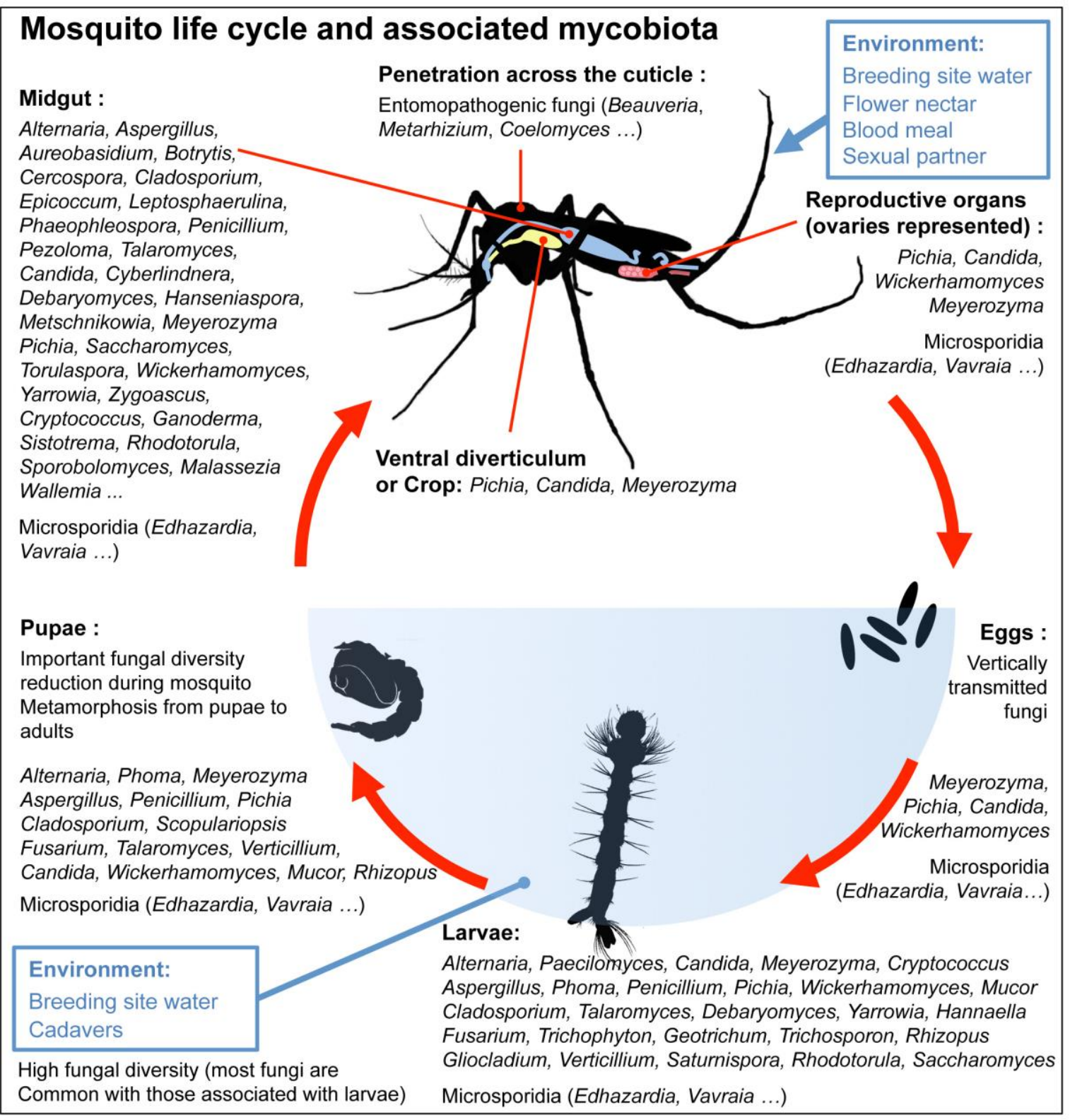

Figure 1. Mosquito-borne diseases with significant public health concern and mycobiota detected along the mosquito life cycle. Given fungal genera are not exhaustive as there are too many genera detected in the adult mosquito (especially in the midgut). To avoid a surcharge of information, only fungal genera detected after gut dissection and/or corresponding to prevalent species (i.e., fungal species found in more than $70 \%$ of mosquito individuals) were included. The complete list of fungal genera and species are given in Supplementary Data (see Table S1). 
In the past decades, mosquito vectors have expanded their global distribution [4,5], favored by global warming and human activities such as international trade or urban expansion [6-8]. This leads to the emergence of mosquito-borne diseases in new geographic areas and causes major public health concerns [3]. In the absence of effective preventive treatments against most pathogens transmitted, vector control remains one of the most suitable strategies against mosquito-borne diseases. The overuse of chemical insecticides in recent years has raised resistance to various molecules in mosquito populations as well as having deleterious impacts on the environment and non-target species [9]. Growing knowledge of mosquito biology has allowed the development of alternative control methods. The mosquito can no longer be considered as an isolated entity and instead should be considered as inseparable from its microbiota with which it interacts and forms a holobiont [10]. This associated microbiota is now recognized to influence many aspects of mosquito biology such as development, physiology, survival, immunity or even vector competence [10-12].

Mosquito-associated microbiota is composed of bacteria, fungi, protists, viruses, and nematodes [13-17]. While an increasing number of studies on mosquito-associated microbiota have focused on bacteria, other microbial partners like fungi have been largely neglected [10,12]. Recent studies show the presence of an important fungal diversity in mosquitoes $[14,17,18]$. Mosquito-associated fungal communities (mycobiota) are mainly composed of Ascomycota (73-92\% in Aedes and Culex species) and Basidiomycota (8-25\% in Aedes and Culex species) including yeasts and filamentous species $[14,17,18]$. Mosquito-associated Ascomycota species, detected by culture-dependent or -independent methods, belong mostly to the Pezizomycotina and Saccharomycotina subphyla [14,17-28]. Among them (see Table S1), several species of filamentous fungi (Aspergillus gracilis, A. puulaauensis, Cladosporium sp., Phaeophleospora hymenocallidicola, Penicillium sp.) and yeasts (Aureobasidium pullulans, Candida parapsilosis, Candida sp., Pichia burtonii) are highly prevalent in mosquito populations and were detected in more than $70 \%$ of mosquito individuals $[14,16,17,29,30]$. Concerning Basidiomycota, mosquito-associated species are mainly affiliated to Agaricomycotina, Ustilaginomycotina and Pucciniomycotina subphyla [14,18,28-31]. Furthermore, yeasts or yeast-like fungi are an important component as they represent on average $19-47 \%$ of the mosquito mycobiota and can even reach $84 \%$ in certain Aedes albopictus populations [14]. Mosquito larvae acquire their gut mycobiota mainly from the water of breeding sites while adults obtain it from water at emergence as well as from sugar (plants or flower nectars) and/or blood meals for females during their entire life span $[29,32,33]$. As observed for bacteria, structure and abundance of fungal communities vary according to stage of development with a significant reduction of fungal diversity in newly emerged adults as the midgut undergoes a partial sterilization during metamorphosis from pupae to adult (Figure 1) [32,34]. Blood ingestion by female mosquitoes also induces a reduction of fungal diversity in the midgut by favoring the development of a few species such as Meyerozyma spp. [18]. In addition to the midgut, fungi also colonize other mosquito organs such as the ventral diverticulum and reproductive organs [35-37].

Mosquitoes and their associated fungi establish different categories of associations ranging along a continuum from parasitic to nonpathogenic interactions. Parasitic interactions include entomopathogenic filamentous fungi, not considered in the present review as they are widely documented because of their potential for mosquito control, and the obligate intracellular parasite microsporidia known to induce negative effects on mosquito biology [24,38,39]. Fungi have also developed commensal or symbiotic relationships with mosquitoes and are then considered as nonpathogenic [32,37]. Knowledge on the role of mycobiota in the development, physiology or immunity of their mosquito host, as well as interference with transmitted pathogens, is henceforth essential to promote the development of new vector control strategies. This review presents key advances and progress in the field of mosquito mycobiota research highlighting the impact of nonpathogenic fungi, including certain microsporidia with non-deleterious effects, on mosquito life-history traits (development, survival, reproduction), vector competence and behavior. 


\section{Influence of Mycobiota on Mosquito Life-History Traits and Digestive Processes}

\subsection{Impact on Development, Survival and Reproduction}

As already mentioned, mosquito larvae acquire their gut mycobiota mainly from breeding-sites feeding on fungi that naturally colonize these aqueous environments [32]. It was also demonstrated that female mosquitoes might transmit some bacteria to their offspring through a mechanism of egg-smearing [40]. However, no study has yet investigated whether such a mechanism could also be applied for fungi. Moreover, females may die after laying their eggs and can often be found floating on water surfaces. This provides opportunities for fungi associated with adult mosquitoes to colonize new habitats and larvae that live inside [32]. Microbiota, and by extension mycobiota, is essential for an optimal development of larvae. It was demonstrated that axenic larvae (microbiota-free larvae) exhibit delays in growth of more than six days [41] compared to conventional ones, or do not develop beyond the first instar [42], despite the presence of an excess of sterile food. Similar to other insects feeding exclusively on blood or phloem, the diet of mosquitoes is deficient in several nutrients. In this way, associated fungi like yeasts provide dietary supplementation thanks to their ability to produce essential amino acids, B vitamins, proteins and trace minerals [43]. A recent study has shown that the yeasts Saccharomyces cerevisiae and Pseudozyma sp. constitute a microbial diet with the highest amounts of proteins and carbohydrates that promotes accumulation of energy reserves (proteins, glycogen, lipids) and development of non-axenic Aedes aegypti larvae [44]. Reserve accumulation is essential to allow larvae to reach a critical mass required to complete their metamorphosis to an adult. Concerning Ae. aegypti, the minimum critical mass is estimated between 2.7 and $3.2 \mathrm{mg}$ [45]. If larvae that have been fed S. cerevisiae or Pseudozyma sp. showed a developmental delay of two to three days compared to those fed fish food, $95-100 \%$ reached the pupal stage and $85-100 \%$ the adult stage [44]. Another study observed variations in terms of survival and development time of $C x$. pipiens depending on yeast species [32]. Indeed, if Metschnikowia bicuspidata and Wickerhamomyces anomalus promote survival (70 to $80 \%$ ) and development of non-axenic Culex pipiens larvae (10-15\% of larvae achieving their pupal stage), Cryptococcus gattii impacts negatively on pupation (no pupae observed) and larval survival (less than $30 \%$ ) [32].

In addition to their nutritional role, yeasts can also be involved in the induction of gut hypoxia functions in mosquitoes. It was shown that S. cerevisiae induces a hypoxia in the gut of Ae. Aegypti, working as a signal for growth and molting [42]. By metabolizing carbohydrates into carbon dioxide $\left(\mathrm{CO}_{2}\right)$ and water during aerobic respiration, yeasts reduce gut oxygen levels below $5 \%$. Gut hypoxia activates hypoxia-induced transcription factors (HIFs) that stimulate signal transduction cascade leading to the accumulation of neutral lipids in the fat body and molting $[42,46,47]$. Such a mechanism could be extended to all mosquito species as the development of axenic $C x$. pipiens larvae is also promoted by the presence of S. cerevisiae [34]. Regarding adult mosquitoes, the microbiota exclusively composed of yeasts maintains a high percentage of survival (68-100\%) but reduces their longevity by some days $[42,44]$.

Fungi can also have a significant impact on the fecundity of female mosquitoes, which refers to the number of eggs laid by each female at one time. Aedes aegypti females infected by the obligate parasite Edhazardia aedis (microsporidia) imbibe 23\% less blood and reduce by $30 \%$ the number of eggs produced [48]. This negative impact of microsporidia increases with age as Anopheles gambiae females infected by Vavraia culicis show a reduction in the number of eggs laid of $16 \%$ during the first laying and of $45 \%$ during the fourth [49]. The localization of the yeast $W$. anomalus in the reproductive organs of both female and male Anopheles stephensi mosquitoes may suggest their potential involvement in mosquito reproduction and their probable vertical transmission [37]. The detection of $W$. anomalus in midgut of pre-adult stages (larvae L1-L4 and pupae) and adults that have emerged under laboratory-controlled conditions (i.e., mosquitoes exclusively fed with sterile food and reared in absence of W. anomalus in larval breeding water) supports the hypothesis of transstadial transmission. Moreover, the presence of 
W. anomalus in adults up to at least ten days post emergence confirms its ability to persist in the midgut and benefit from nutrients in the mosquito diet [37].

\subsection{Mutualistic Interactions and Their Role in Digestive Processes}

Fungi and mosquitoes mostly establish trophic interactions that improve the acquisition of nutrients and energy for both partners [50]. Both male and female mosquitoes feed on plant nectar, fruit juices, plant sap and honeydew that contain mainly sugars such as glucose, fructose, and sucrose [33]. Following ingestion, a part of these sugars is directly digested by salivary enzymes and assimilated by the mosquito [51]. The other part is stored in the ventral diverticulum (or crop), which is an extension of the foregut near the esophagus and from which several yeasts like Pichia caribbica and Candida etchellsii have been isolated [35]. Sugars are then progressively transported from the crop to the gut to be digested, absorbed and used as a regular energy source for both the host and active gut microbiota (including fungi) [50-52]. In return, the active mycobiota might provide essential nutrients to the mosquito such as amino acids or B vitamins as already observed in other insect models [43]. Differences in the composition of fungal communities assimilating the fructose in $A e$. albopictus were highlighted according to the sex of mosquito [50]. Whereas Malassezia yeasts have been shown to actively metabolize the fructose in males and females, Cyberlindnera yeasts as well as the filamentous fungi belonging to Pezoloma and Ganoderma genera appeared particularly active in females. Moreover, Aspergillus and Cladosporium genera have been identified as the most active in males [50]. These differences in community composition could be partly explained by competition and synergy phenomena within the fungal community or more generally within the microbiota for fructose assimilation.

Malpighian tubules play key roles in diuresis and detoxification of the uric acid, which is accumulated in these structures within $24 \mathrm{~h}$ after a blood meal [53]. In the sand fly Phlebotomus perniciosus, the main vector of leishmaniasis in the western Mediterranean area, it was recently showed that the yeast Meyerozyma guilliermondii colonizes the midgut of adults and larvae as well as the distal part of the Malpighian tubules of females. Moreover, M. guilliermondii possesses an uricolytic activity and presents in its genome the complete uric acid degradation pathway suggesting that this yeast might contribute to the removal of the excess of uric acid after the blood meal of the insect host [54]. Interestingly, M. guilliermondii has been also detected in several mosquito species [29,32] and might also be involved in the degradation of the uric acid accumulated in the Malpighian tubules after the blood meal. Other mosquito inhabiting yeasts, such as W. anomalus, are able to withstand high concentrations of uric acid and should therefore possess the complete degradation pathway [37].

\section{Influence of Mosquito-Associated Mycobiota on Vector Competence}

\subsection{Direct Impact through the Production of Fungal Toxins or the Modulation of Enzymatic Activities}

Some strains of $W$. anomalus inhabiting the midgut and gonads of Anopheles mosquitoes are able to produce lethal toxins that exert a wide spectrum anti-microbial activity and are often referred as to "killer yeasts" [37,55]. This killing mechanism, which could protect Anopheles mosquitoes from infection by entomopathogenic fungi, is partly based on an exo- $\beta-1,3$-glucanase enzymatic activity of the toxins [56]. Due to their presence in the midgut and the exo- $\beta-1,3$-glucanase enzymatic activity of their toxins, these $W$. anomalus strains strongly inhibit the development of Plasmodium berghei from gametocytes to ookinetes in females [57]. Parasite death is induced by the hydrolysis of the $\beta$-glucans located in cell-wall membranes of parasites. It was shown that yeasts could reduce the number of parasites (zygotes and ookinetes) by 65\% [57]. Contrary to the observations made in vitro [56], no parasitic effect has been shown in vivo on oocysts and sporozoites. This lack of effect could be explained by the fact that these two stages of the sporogonic phase are located outside the lumen of the midgut and therefore never come into contact with yeast toxins [57]. 
Conversely, other fungi can favor pathogen development in mosquitoes. For example, the filamentous fungus Talaromyces sp. that naturally colonizes the midgut of Ae aegypti promotes mosquito infection with Dengue virus by inhibiting gut digestive enzyme activities and also enhances Plasmodium infection in An. gambiae [58]. Secretion of heat-sensitive metabolites and/or proteins by the fungus induces the repression of genes encoding several trypsins and endo-proteases involved in the blood meal digestion. In addition, these fungal metabolites were also shown to alter trypsin activity [58].

\subsection{Indirect Impact through the Modulation of the Immune System}

Like all insects, mosquitoes only possess innate cellular and humoral immunity, which is a direct response to an infectious agent, nonspecific and not influenced by prior acquired antigen interactions, contrary to adaptive immunity [59]. Innate immunity is based on the recognition of highly conserved molecular patterns restricted to microbes, e.g., MAMPS (Microbe Associated Molecular Patterns), which are recognized by a set of receptors found on the cell surface of host cells, e.g., PRRs (Pattern Recognition Receptors). The ability of fungal partners to stimulate the mosquito immune system has been studied mainly in entomopathogenic fungi [60]. Detection of fungal surface molecules and secreted secondary metabolites by specific receptors in mosquitoes induces the activation of kinases or transcription factors, which stimulate the production of antimicrobial peptides (defensins, cecropins, diptericins, gambicins) or other effector molecules as well as melanization and phagocytosis of fungal cells (Figure 2). Fungi can stimulate different immune signaling pathways in the midgut and/or fat body such as Toll, Imd (Immune Deficiency), JAK/STAT (Janus Kinase/Signal Transducer and Activator of Transcription), JNK/MAPKp38 (Jun N-terminal Kinase/Mitogen Activated Protein Kinase p38), TEP (ThioEster-containing Protein) and immune melanization proteases [60]. The presence of non-entomopathogenic fungi, such as S. cerevisiae and Candida albicans, in the hemolymph of Anopheles albimanus and Culex quinquefasciatus mosquitoes induces the melanization of fungal cells after their recognition by proteins containing thioesters (TEPs). This results in the death of fungal cells from lack of nutrients without being phagocytized by hemocytes [61,62]. Fungi may therefore interfere with vector competence by promoting or inhibiting the mosquito immune system. In An. gambiae, microsporidia with non-deleterious effects such as Vavraia culicis inhibit $P$. berghei development through the stimulation of immune responses such as melanization reaction. It was shown that the number of oocysts in microsporidian-infected mosquitoes is strongly reduced compared to uninfected ones (58\% vs. $81 \%$ ) [63]. Similarly, Microsporidia MB, which is another example of microsporidia with non-deleterious effects, is found in the midgut and ovaries of Anopheles arabiensis and alters the development of Plasmodium falciparum by stimulating the expression of genes encoding digestive enzymes such as serine proteases, as well as the immune response (cecropins and gambicins) [64]. Strains of $W$. anomalus unable to produce killer toxins reduce the intensity of $P$. berghei infection in Anopheles mosquitoes by $38 \%$ probably through the activation of the mosquito immune system [57]. Other mechanisms used by fungi to inhibit Plasmodium development or viral replication in mosquitoes could involve resource competition and production of cyanide or reactive oxygen species as already observed for bacteria [65,66]. Conversely, the filamentous fungus Penicillium chrysogenum makes An. gambiae more susceptible to infection with $P$. falciparum. Using arginine for polyamine synthesis, $P$. chrysogenum prevents nitric oxide production, which is considered as the principal anti-Plasmodium defense system in the mosquito [67]. 


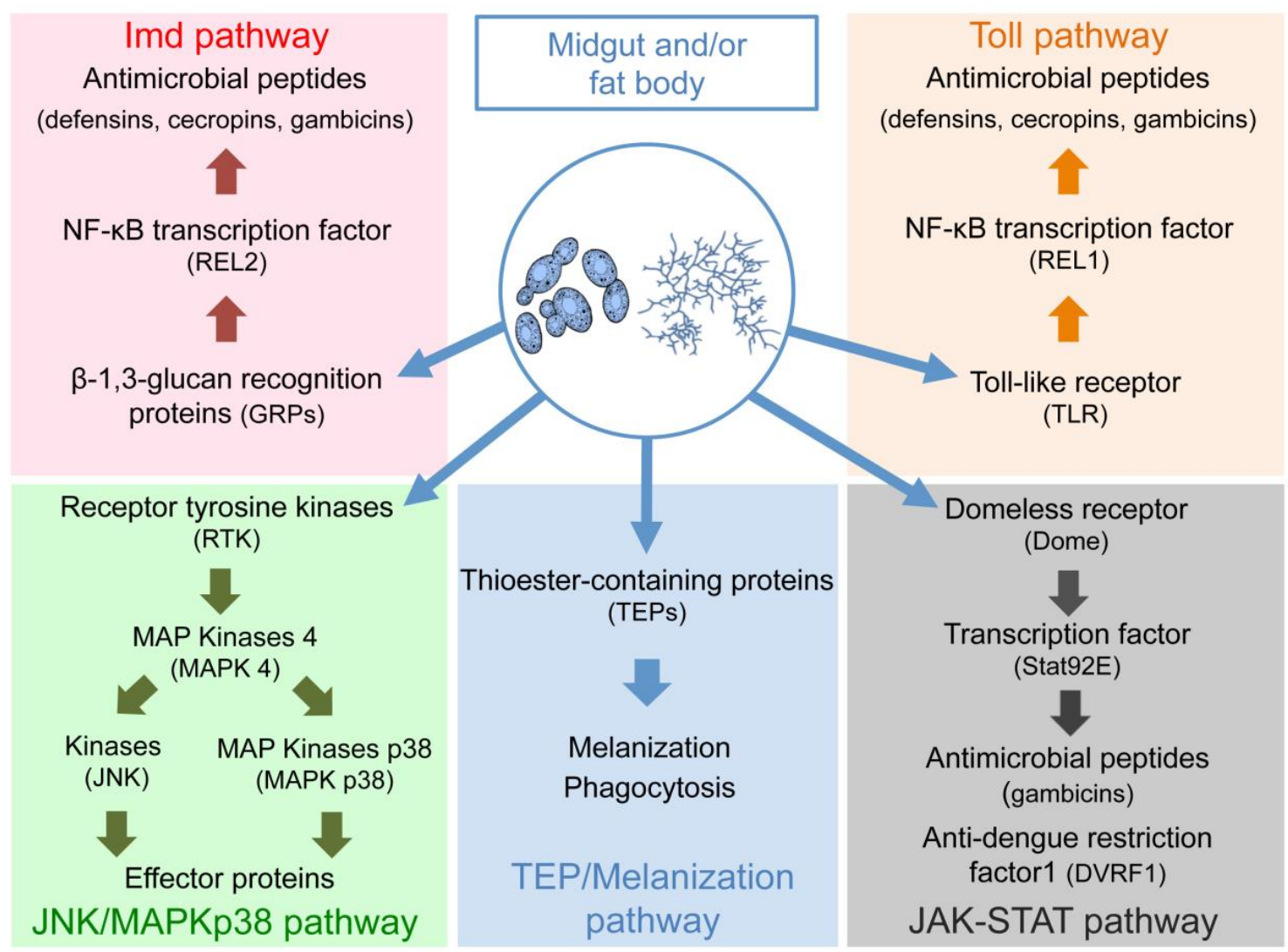

Figure 2. Signaling pathways of mosquito's innate immunity stimulated by fungi. Fungal surface molecules or secondary metabolites are recognized by specific receptors. This recognition induces the activation of kinases or transcription factors that stimulate the production of antimicrobial peptides or other effector proteins as well as melanization and phagocytosis of fungal cells. Toll, Imd (Immune Deficiency), JAK/STAT (Janus Kinase/Signal Transducer and Activator of Transcription), JNK/MAPKp38 (Jun N-terminal Kinase/Mitogen Activated Protein Kinase p38), TEP (ThioEstercontaining Protein) and immune melanization proteases are the different signaling pathways stimulated by fungi.

\section{Influence of Fungi and Their Associated Volatile Compounds on Mosquito Behavior}

\subsection{Attractive or Repulsive Effects and Impact on Breeding Site Selection}

Mosquitoes use various signals (visual, humidity, olfactory, etc.) to find their food sources (vertebrate host and/or nectar) and mating partner as well as to locate a place to oviposit (Figure 3) [68]. Chemical cues mainly include $\mathrm{CO}_{2}$ and volatile organic compounds (VOCs) able to modulate mosquito behavior such as feeding, mating and egg laying. If plants and vertebrate hosts directly emit some of these chemical volatiles, a part of these compounds is also produced by human or animal skin microbiota, as well as nectar-colonizing microorganisms $[69,70]$. This is the case of fungal partners, and more particularly yeasts, which produce $\mathrm{CO}_{2}$ and volatile secondary metabolites as by-products during fermentation that attract many insects including mosquitoes [33,71-73]. In addition to the presence of VOCs, it was demonstrated that $\mathrm{CO}_{2}$ produced by yeasts during fermentative metabolism of different carbon sources attracts significantly more mosquitoes than industrial $\mathrm{CO}_{2}$ or octenol (fungal aromatic compound) used alone [74-77]. However, according to the mosquito species, the nature of the VOCs and their concentration, mosquitoes can be attracted as well as repelled [73]. Even if the fermentation of honey by yeast produces higher amounts of VOCs, including many attractive compounds such as hexanoic acid or phenylethyl alcohol, sucrose and molasses are more attractive to mosquitoes. In that case, the absence of some VOCs with repellent properties could favor mosquito attraction [73]. Fungal 
spores, such as those of the entomopathogenic species Beauveria bassiana and Metarhizium anisopliae, attract An. stephensi females by producing VOCs that have not been yet identified [78].

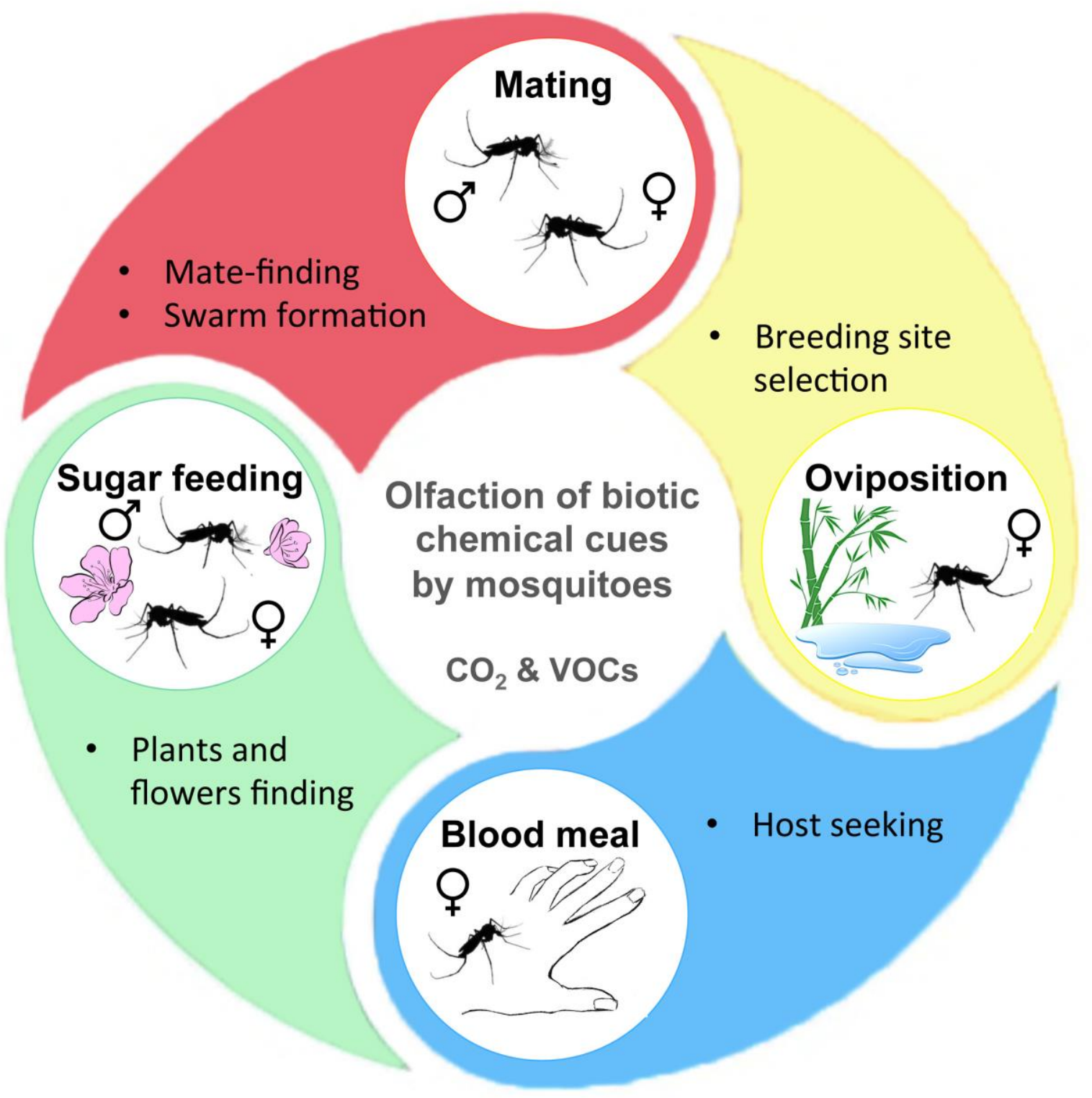

Figure 3. Influence of fungal volatile compounds on mosquito behavior. Mosquitoes use olfactory perception of chemical cues and signals, such as $\mathrm{CO}_{2}$ or volatile organic compounds (VOCs), to efficiently find flowering plants, mating partners, vertebrate hosts or breeding sites favorable for larval development. The figure was adapted from Wooding et al. [68] with permission.

Gravid mosquito females assess the suitability and accessibility of oviposition sites by physical cues and semio-chemicals released from larvae, eggs and/or of microbial origin [68]. Gravid Ae. aegypti females prefer breeding sites that contain eggs of the same species and larvae that are not starving or not infected with a deleterious parasite [79]. Aedes aegypti mosquitoes are naturally colonized by the yeast Candida pseudoglaebosa and it was shown that the presence of this yeast in the water of breeding sites attracts gravid females for oviposition [79]. Conversely, S. cerevisiae, which is not a member of the mosquito gut mycobiota, does not seem to attract ovipositing $C x$. pipiens females to the breeding site [34]. It was also demonstrated that secondary metabolites produced by the saprotrophic fungus Trichoderma viride would attract $76 \%$ of gravid $C x$. quinquefasciatus females [80]. Similarly, the two 
filamentous fungi Fusarium fujikuroi and Fusarium falciforme known to colonize rhizomes of the grass Cyperus rotundus, which is found in natural Anopheles larval habitats, are able to emit VOCs and in particular cedrol that attracts gravid An. gambiae females [81,82].

\subsection{Impact on Larval and Adult Feeding Behavior}

As mentioned above, mosquitoes are attracted by $\mathrm{CO}_{2}$ and VOC emissions from plant mycobiota and more particularly nectar-inhabiting yeasts [33,70]. These fungal volatile compounds signal the presence of sugar sources to the insect and allow yeasts to be dispersed during insect foraging [71,72]. This behavior explains the presence in the mosquito mycobiota of many phytopathogenic fungi and yeasts known to inhabit floral nectar [14,17]. Microsporidia infection impacts the frequency of blood meal in gravid females. For example, Edhazardia aedis strongly reduce the amount of blood ingested by Ae aegypti, females as well as the number of laid eggs [48]. As previously stated, yeasts are able to promote larval development through nutrient intake and energetic accumulation in the mosquito $A e$. aegypti [44]. Interestingly, in Anopheles mosquitoes, it was also demonstrated that larvae responded to the presence of yeasts recognized as potential behaviorally active odorants $[83,84]$. Contrary to the insect repellent DEET, S. cerevisiae slow down the average velocity of movements of larvae as well as their body rotations while increasing the rest time [84].

\section{Conclusions}

Mosquito population control is an essential step for arboviral disease transmission management. Compared to the overuse of insecticides, the identification and utilization of associated-fungi that could reduce mosquito development and arbovirus transmission or impact their behavior might be an environmentally friendly strategy for controlling vector-borne diseases. Despite the growing number of studies concerning the impact of nonpathogenic fungi on the biology of mosquitoes, they are still scarce. Moreover, these studies concern only few fungal species including the yeast $S$. cerevisiae, which is not a member of the mosquito gut mycobiota. Additionally, most studies focused on An. gambiae, $C x$. pipiens, $C x$. quinquefasciatus and Ae. aegypti mosquitoes and largely ignored the tiger mosquito $A e$. albopictus considered nowadays as one of the most invasive species. Further knowledge concerning the impact of nonpathogenic fungi on life-history traits, vector competence and behavior of mosquitoes is henceforth essential to be able to develop new vector control strategies. For example, yeasts are often used in attractive baits to generate biogenic $\mathrm{CO}_{2}$. Better knowledge of yeasts and their associated emitted VOCs might improve these techniques and open new avenues for the development of efficient mosquito control methods.

Supplementary Materials: The following are available online at http://www.mdpi.com/2076-0817/9/7/564/s1, Table S1: Overview of mosquito-associated fungal species found either in laboratory or field populations. Entomopathogenic fungi and obligate intracellular parasites (Microsporidia) are not included. All fungal species have been identified, using culture-dependent or -independent methods, either after mosquito surface sterilization only or after internal organ dissection.

Author Contributions: S.M., C.V.M. and P.L. wrote the paper. S.M. and P.L. made the figures. All authors have read and agreed to the published version of the manuscript.

Funding: This study was funded by the Scientific Breakthrough Program Micro-be-have (IDEX Lyon-Université de Lyon).

Acknowledgments: We thank Muhammad Mahdi Karim, Aleksandrs Balodis and Jean-Marie Hosatte for given us the permission to use their mosquito pictures. We are also grateful to Madelien Wooding, Yvette Naudé, Egmont Rohwer and Marc Bouwer, who allow us to adapt one of their published figures for the present review.

Conflicts of Interest: The authors declare no conflict of interest.

\section{References}

1. Forster, W.A.; Walker, E.D. Mosquitoes (Culicidae). In Medical and Veterinary Entomology, 3rd ed.; Mullen, G.R., Durden, L.A., Eds.; Academic Press Elsevier: Oxford, UK, 2018; Volume 1, pp. 261-325. 
2. Clements, A.N. (Ed.) Development, nutrition and reproduction. In The Biology of Mosquitoes, 1st ed.; CABI Publishing: Wallingford, UK, 1992; Volume 1, pp. 1-532.

3. Gao, H.; Cui, C.; Wang, L.; Jacobs-Lorena, M.; Wang, S. Mosquito microbiota and implications for disease control. Trends Parasitol. 2020, 36, 98-111. [CrossRef]

4. Ciota, A.T.; Kramer, L.D. Vector-virus interactions and transmission dynamics of West Nile virus. Viruses 2013, 5, 3021-3047. [CrossRef]

5. Sinka, M.E.; Bangs, M.J.; Manguin, S.; Rubio-Palis, Y.; Chareonviriyaphap, T.; Coetzee, M.; Mbogo, C.M.; Hemingway, J.; Patil, A.P.; Temperley, W.H.; et al. A global map of dominant malaria vectors. Parasit. Vectors 2012, 5, 69. [CrossRef] [PubMed]

6. Hongoh, V.; Berrang-Ford, L.; Scott, M.E.; Lindsay, L.R. Expanding geographical distribution of the mosquito, Culex pipiens, in Canada under climate change. Appl. Geogr. 2012, 33, 53-62. [CrossRef]

7. Caminade, C.; Kovats, S.; Rocklov, J.; Tompkins, A.M.; Morse, A.P.; Colón-González, F.J.; Stenlund, H.; Martens, P.; Lloyd, S.J. Impact of climate change on global malaria distribution. Proc. Natl. Acad. Sci. USA 2014, 111, 3286-3291. [CrossRef] [PubMed]

8. Kraemer, M.U.G.; Reiner, R.C.; Brady, O.J.; Messina, J.P.; Gilbert, M.; Pigott, D.M.; Yi, D.; Johnson, K.; Earl, L.; Marczak, L.B.; et al. Past and future spread of the arbovirus vectors Aedes aegypti and Aedes albopictus. Nat. Microbiol. 2019, 4, 854-863. [CrossRef] [PubMed]

9. Karunaratne, S.H.P.P.; De Silva, W.A.P.P.; Weeraratne, T.C.; Surendran, S.N. Insecticide resistance in mosquitoes: Development, mechanisms and monitoring. Ceylon. J. Sci. 2018, 47, 299-309. [CrossRef]

10. Guégan, M.; Zouache, K.; Démichel, C.; Minard, G.; Tran Van, V.; Potier, P.; Mavingui, P.; Valiente Moro, C. The mosquito holobiont: Fresh insight into mosquito-microbiota interactions. Microbiome 2018, 6, 49. [CrossRef]

11. Minard, G.; Mavingui, P.; Valiente Moro, C. Diversity and function of bacterial microbiota in the mosquito holobiont. Parasit. Vectors 2013, 6, 146. [CrossRef]

12. Scolari, A.; Casiraghi, M.; Bonizzoni, M. Aedes spp. and their microbiota: A review. Front. Microbiol. 2019, 10, 2036. [CrossRef]

13. Minard, G.; Tran, F.H.; Van, V.T.; Goubert, C.; Bellet, C.; Lambert, G.; Kim, K.L.; Thuy, T.H.; Mavingui, P.; Valiente Moro, C. French invasive Asian tiger mosquito populations harbor reduced bacterial microbiota and genetic diversity compared to Vietnamese autochthonous relatives. Front. Microbiol. 2015, 6, 970. [CrossRef] [PubMed]

14. Luis, P.; Vallon, L.; Tran, F.-H.; Hugoni, M.; Tran-Van, V.; Mavingui, P.; Minard, G.; Valiente Moro, C. Aedes albopictus mosquitoes host a locally structured mycobiota with evidence of reduced fungal diversity in invasive populations. Fungal Ecol. 2019, 39, 257-266. [CrossRef]

15. Morales, M.E.; Ocampo, C.B.; Cadena,H.; Copeland,C.S.; Termini, M.; Wesson, D.M. Differential identification of Ascogregarina species (Apicomplexa: Lecudinidae) in Aedes aegypti and Aedes albopictus (Diptera: Culicidae) by Polymerase Chain Reaction. J. Parasitol. 2005, 91, 1352-1357. [CrossRef] [PubMed]

16. Chandler, J.A.; Liu, R.M.; Bennett, S.N. RNA shotgun metagenomic sequencing of northern California (USA) mosquitoes uncovers viruses, bacteria, and fungi. Front. Microbiol. 2015, 6, 185. [CrossRef]

17. Thongsripong, P.; Chandler, J.A.; Green, A.B.; Kittayapong, P.; Wilcox, B.A.; Kapan, D.D.; Bennett, S.N. Mosquito vector-associated microbiota: Metabarcoding bacteria and eukaryotic symbionts across habitat types in Thailand endemic for dengue and other arthropod-borne diseases. Ecol. Evol. 2017, 8, 1352-1368. [CrossRef]

18. Muturi, E.J.; Bara, J.J.; Rooney, A.P.; Hansen, A.K. Midgut fungal and bacterial microbiota of Aedes triseriatus and Aedes japonicus shift in response to La Crosse virus infection. Mol. Ecol. 2016, 25, 4075-4090. [CrossRef]

19. Badran, R.A.M.; Aly, M.Z.Y. Studies on the mycotic inhabitants of Culex pipiens collected from fresh water ponds in Egypt. Mycopathologia 1995, 132, 105-110. [CrossRef]

20. Da Costa, G.L.; Cunha de Oliveira, P. Penicillium species in mosquitoes from two Brazilian regions. J. Basic Microbiol. 1998, 38, 343-347. [CrossRef]

21. Sur, B.; Bihari, V.; Sharma, A.; Basu, S.K. Survey of termite-inhabited soil and mosquito breeding sites in Lucknow, India for potential mycopathogens of Anopheles stephensi. Mycopathologia 1999, 144, 77-80. [CrossRef]

22. Agarwala, S.P.; Sagar, S.K.; Sehgal, S.S. Use of mycelial suspension and metabolites of Paecilomyces lilacinus (Fungi: Hyphomycetes) in control of Aedes aegypti larvae. J. Commun. Dis. 1999, 31, 193-196. 
23. Mohanty, S.S.; Prakash, S. Laboratory evaluation of Trichophyton ajelloi, a fungal pathogen of Anopheles stephensi and Culex quinquefasciatus. J. Am. Mosquito Control. 2000, 16, $254-257$.

24. Scholte, E.J.; Knols, B.G.J.; Samson, R.A.; Takken, W. Entomopathogenic fungi for mosquito control: A review. J. Insect. Sci. 2004, 4, 19. [CrossRef] [PubMed]

25. Pereira, E.D.; Sarquis, M.I.; Ferreira-Keppler, R.L.; Hamada, N.; Alencar, Y.B. Filamentous fungi associated with mosquito larvae (Diptera: Culicidae) in municipalities of the Brazilian Amazon. Neotrop. Entomol. 2009, 38, 352-359. [CrossRef] [PubMed]

26. Bishop-Lilly, K.A.; Turell, M.J.; Willner, K.M.; Butani, A.; Nolan, N.M.E.; Lentz, S.M.; Akmal, A.; Mateczun, A.I.; Brahmbhatt, T.N.; Sozhamannan, S.; et al. Arbovirus detection in insect vectors by rapid high—throughput pyrosequencing. PLoS Negl. Trop. Dis. 2010, 4, e878. [CrossRef]

27. Belda, E.; Coulibaly, B.; Fofana, A.; Beavogui, A.H.; Traore, S.F.; Gohl, D.M.; Vernick, K.D.; Riehle, M.M. Preferential suppression of Anopheles gambiae host sequences allows detection of the mosquito eukaryotic microbiome. Sci. Rep. 2017, 7, 3241. [CrossRef]

28. Krajacich, B.J.; Huestis, D.L.; Dao, A.; Yaro, A.S.; Diallo, M.; Krishna, A.; Xu, J.; Lehmann, T. Investigation of the seasonal microbiome of Anopheles coluzzii mosquitoes in Mali. PLoS ONE 2018, 13, e0194899. [CrossRef]

29. Bozic, J.; Capone, A.; Pediconi, D.; Mensah, P.; Cappelli, A.; Valzano, M.; Mancini, M.V.; Scuppa, P.; Martin, E.; Epis, S.; et al. Mosquitoes can harbour yeasts of clinical significance and contribute to their environmental dissemination: Identification of yeasts in different mosquito species. Environ. Microbiol. Rep. 2017, 9, 642-648. [CrossRef]

30. Frants, T.G.; Mertvetsova, O.A. Yeast associations with mosquitoes of the genus Aedes Mg. (Diptera, Culicidae) in the Tom-Ob river region. Nauchnye Doklady Vysshei Shkoly Biologicheskie Nauki 1986, 4, 94-98.

31. Ignatova, E.A.; Nagomaia, S.S.; Povazhnaia, T.N.; Ianishevskaia, G.S. The yeast flora of blood-sucking mosquitoes. Microbiol. Z 1996, 58, 12-15.

32. Steyn, A.; Roets, F.; Botha, A. Yeasts associated with Culex pipiens and Culex theileri mosquito larvae and the effect of selected yeast strains on the ontogeny of Culex pipiens. Microb. Ecol. 2016, 71, 747-760. [CrossRef]

33. Barredo, E.; DeGennaro, M. Not just from blood: Mosquito nutrient acquisition from nectar sources. Trends Parasitol. 2020, 36, 473-484. [CrossRef] [PubMed]

34. Díaz-Nieto, L.M.; D'Alessio, C.; Perotti, M.A.; Berón, C.M. Culex pipiens development is greatly influenced by native bacteria and exogenous yeast. PLoS ONE 2016, 11, e0153133. [CrossRef] [PubMed]

35. Gusmão, D.S.; Santos, A.V.; Marini, D.C.; Russo Ede, S.; Peixoto, A.M.; Bacci Júnior, M.; Berbert-Molina, M.A.; Lemos, F.J. First isolation of microorganisms from the gut diverticulum of Aedes aegypti (Diptera: Culicidae): New perspectives for an insect-bacteria association. Memórias do Instituto Oswaldo Cruz 2007, 102, 919-924.

36. Gusmão, D.S.; Santos, A.V.; Marini, D.C.; Bacci, M., Jr.; Berbert-Molina, M.A.; Lemos, F.J. Culture-dependent and culture-independent characterization of microorganisms associated with Aedes aegypti (Diptera: Culicidae) (L.) and dynamics of bacterial colonization in the midgut. Acta Trop. 2010, 115, 275-281.

37. Ricci, I.; Damiani, C.; Scuppa, P.; Mosca, M.; Crotti, E.; Rossi, P.; Rizzi, A.; Capone, A.; Gonella, E.; Ballarini, P.; et al. The yeast Wickerhamomyces anomalus (Pichia anomala) inhabits the midgut and reproductive system of the Asian malaria vector Anopheles stephensi. Environ. Microbiol. 2011, 13, 911-921. [CrossRef]

38. Bukhari, T.; Takken, W.; Koenraadt, C.J.M. Development of Metarhizium anisopliae and Beauveria bassiana formulations for control of malaria mosquito larvae. Parasit. Vectors 2011, 4, 23. [CrossRef]

39. Becnel, J.J.; White, S.E.; Shapiro, A.M. Review of microsporidia-mosquito relationships: From the simple to the complex. Folia Parasitol. 2005, 52, 41-50. [CrossRef]

40. Damiani, C.; Ricci, I.; Crotti, E.; Rossi, P.; Rizzi, A.; Scuppa, P.; Capone, A.; Ulissi, U.; Epis, S.; Genchi, M.; et al. Mosquito-bacteria symbiosis: The case of Anopheles gambiae and Asaia. Microb. Ecol. 2010, 60, 644-654. [CrossRef]

41. Corréa, M.A.; Matusovsky, B.; Brackney, D.E.; Steven, B. Generation of axenic Aedes aegypti demonstrate live bacteria are not required for mosquito development. Nat. Commun. 2018, 9, 4464. [CrossRef]

42. Valzania, L.; Martinson, V.G.; Harrison, R.E.; Boyd, B.M.; Coon, K.L.; Brown, M.R.; Strand, M.R. Both living bacteria and eukaryotes in the mosquito gut promote growth of larvae. PLoS Negl. Trop. Dis. 2018, 12, e0006638. [CrossRef]

43. Stefanini, I. Yeast-insect associations: It takes guts. Yeast 2018, 35, 315-330. [CrossRef] [PubMed] 
44. Souza, R.S.; Virginio, F.; Riback, T.I.S.; Suesdek, L.; Barufi, J.B.; Genta, F.A. Microorganism-based larval diets affect mosquito development, size and nutritional reserves in the yellow fever mosquito Aedes aegypti (Diptera: Culicidae). Front. Physiol. 2019, 10, 152. [CrossRef] [PubMed]

45. Telang, A.; Frame, L.; Brown, M.R. Larval feeding duration affects ecdysteroid levels and nutritional reserves regulating pupal commitment in the yellow fever mosquito Aedes aegypti (Diptera: Culicidae). J. Exp. Biol. 2007, 210, 854-864. [CrossRef] [PubMed]

46. Valzania, L.; Coon, K.L.; Vogel, K.J.; Brown, M.R.; Strand, M.R. Hypoxia-induced transcription factor signaling is essential for larval growth of the mosquito Aedes aegypti. Proc. Natl. Acad. Sci. USA 2018, 115, 457-465. [CrossRef] [PubMed]

47. Strand, M.R. Composition and functional roles of the gut microbiota in mosquitoes. Curr. Opin. Insect. Sci. 2018, 28, 59-65. [CrossRef]

48. Barnard, D.R.; Xue, R.-D.; Rotstein, M.A.; Becnel, J.J. Microsporidiosis (Microsporidia: Culicosporidae) alters blood-feeding responses and DEET repellency in Aedes aegypti (Diptera: Culicidae). J. Med. Entomol. 2007, 44, 1040-1046. [CrossRef]

49. Lorenz, L.M.; Koella, J.C. The microsporidian parasite Vavraia culicis as a potential late life-acting control agent of malaria. Evol. Appl. 2011, 4, 783-790. [CrossRef]

50. Guégan, M.; Tran Van, V.; Martin, E.; Minard, G.; Tran, F.; Fel, B.; Hay, A.; Simon, L.; Barakat, M.; Potier, P.; et al. Who is eating fructose within the Aedes albopictus gut microbiota? Environ. Microbiol. 2020, 22, 1193-1206. [CrossRef]

51. Foster, W.A. Mosquito sugar feeding and reproductive energetics. Annu. Rev. Entomol. 1995, 40, $443-474$. [CrossRef]

52. Souza-Neto, J.A.; Machado, F.P.; Lima, J.B.; Valle, D.; Ribolla, P.E.M. Sugar digestion in mosquitoes: Identification and characterization of three midgut $\alpha$-glucosidases of the neo-tropical malaria vector Anopheles aquasalis (Diptera: Culicidae). Comp. Biochem. Physiol. A Mol. Int. Physiol. 2007, 147, 993-1000. [CrossRef]

53. Esquivel, C.J.; Cassone, B.J.; Piermarini, P.M. A de novo transcriptome of the Malpighian tubules in non blood-fed and blood-fed Asian tiger mosquitoes Aedes albopictus: Insights into diuresis, detoxification, and blood meal processing. Peer] 2016, 4, e1784. [CrossRef] [PubMed]

54. Martin, E.; Varotto Boccazzi, I.; De Marco, L.; Bongiorno, G.; Montagna, M.; Sacchi, L.; Mensah, P.; Ricci, I.; Gradoni, L.; Bandi, C.; et al. The mycobiota of the sand fly Phlebotomus perniciosus: Involvement of yeast symbionts in uric acid metabolism. Environ. Microbiol. 2018, 20, 1064-1077. [CrossRef] [PubMed]

55. Cappelli, A.; Ulissi, U.; Valzano, M.; Damiani, C.; Epis, S.; Gabrielli, M.G.; Conti, S.; Polonelli, L.; Bandi, C.; Favia, G.; et al. A Wickerhamomyces anomalus killer strain in the malaria vector Anopheles stephensi. PLoS ONE 2014, 9, e95988. [CrossRef]

56. Valzano, M.; Cecarini, V.; Cappelli, A.; Capone, A.; Bozic, J.; Cuccioloni, M.; Epis, S.; Petrelli, D.; Angeletti, M.; Eleuteri, A.M.; et al. yeast strain associated to Anopheles mosquitoes produces a toxin able to kill malaria parasites. Malar. J. 2016, 15, 21. [CrossRef] [PubMed]

57. Cappelli, A.; Valzano, M.; Cecarini, V.; Bozic, J.; Rossi, P.; Mensah, P.; Amantini, C.; Favia, G.; Ricci, I. Killer yeasts exert anti-plasmodial activities against the malaria parasite Plasmodium berghei in the vector mosquito Anopheles stephensi and in mice. Parasit. Vectors 2019, 12, 329. [CrossRef] [PubMed]

58. Angleró-Rodríguez, Y.I.; Talyuli, O.A.; Blumberg, B.J.; Kang, S.; Demby, C.; Shields, A.; Carlson, J.; Jupatanakul, N.; Dimopoulos, G. An Aedes aegypti-associated fungus increases susceptibility to dengue virus by modulating gut trypsin activity. Elife 2017, 6, e28844. [CrossRef]

59. Kumar, A.; Srivastava, P.; Sirisena, P.; Dubey, S.K.; Kumar, R.; Shrinet, J.; Sunil, S. Mosquito Innate Immunity. Insects 2018, 9, 95. [CrossRef]

60. Tawidian, P.; Rhodes, V.L.; Michel, K. Mosquito-fungus interactions and antifungal immunity. Insect Biochem. Mol. Biol. 2019, 111, 103182. [CrossRef]

61. Hernández-Martínez, S.; Lanz, H.; Rodrguez, M.H.; González-Ceron, L.; Tsutsumi, V. Cellular-mediated reactions to foreign organisms inoculated into the hemocoel of Anopheles albimanus (Diptera: Culicidae). J. Med. Entomol. 2002, 39, 61-69. [CrossRef]

62. Da Silva, J.B.; De Albuquerque, C.M.R.; De Araújo, E.C.; Peixoto, C.A.; Hurd, H. Immune defense mechanisms of Culex quinquefasciatus (Diptera: Culicidae) against Candida albicans infection. J. Invertebr. Pathol. 2000, 76, 257-262. [CrossRef] 
63. Bargielowski, I.; Koella, J.C. A possible mechanism for the suppression of Plasmodium berghei development in the mosquito Anopheles gambiae by the microsporidian Vavraia culicis. PLoS ONE 2009, 4, e4676. [CrossRef]

64. Herren, J.K.; Mbaisi, L.; Mararo, E.; Makhulu, E.E.; Mobegi, V.A.; Butungi, H.; Mancini, M.V.; Oundo, J.W.; Teal, E.T.; Pinaud, S.; et al. A microsporidian impairs Plasmodium falciparum transmission in Anopheles arabiensis mosquitoes. Nat. Commun. 2020, 11, 2187. [CrossRef] [PubMed]

65. Cirimotich, C.M.; Dong, Y.; Clayton, A.M.; Sandiford, S.L.; Souza-Neto, J.A.; Mulenga, M.; Dimopoulos, G. Natural microbe-mediated refractoriness to Plasmodium infection in Anopheles gambiae. Science 2011, 332, 855-858. [CrossRef]

66. Ramirez, J.L.; Short, S.M.; Bahia, A.C.; Saraiva, R.G.; Dong, Y.; Kang, S.; Tripathi, A.; Mlambo, G.; Dimopoulos, G. Chromobacterium Csp_P reduces malaria and dengue infection in vector mosquitoes and has entomopathogenic and in vitro anti-pathogen activities. PLoS Pathog. 2014, 10, e1004398. [CrossRef]

67. Angleró-Rodríguez, Y.I.; Blumberg, B.J.; Dong, Y.; Sandiford, S.L.; Pike, A.; Clayton, A.M.; Dimopoulos, G. A natural Anopheles-associated Penicillium chrysogenum enhances mosquito susceptibility to Plasmodium infection. Sci. Rep. 2016, 6, 34084. [CrossRef] [PubMed]

68. Wooding, M.; Naudé, Y.; Rohwer, E.; Bouwer, M. Controlling mosquitoes with semiochemicals: A review. Parasit. Vectors 2020, 13, 80. [CrossRef] [PubMed]

69. Verhulst, N.O.; Takken, W.; Dicke, M.; Schraa, G.; Smallegange, R.C. Chemical ecology of interactions between human skin microbiota and mosquitoes. FEMS Microbiol. Ecol. 2010, 74, 1-9. [CrossRef]

70. Peach, D.A.H.; Carroll, C.; Meraj, S.; Gomes, S.; Galloway, E.; Balcita, A.; Coatsworth, H.; Young, N.; Uriel, Y.; Gries, R.; et al. Nectar-dwelling microbes of common tansy are attractive to its mosquito pollinator, Culex pipiens L. bioRxiv 2020, 4, 024380.

71. Becher, P.G.; Hagman, A.; Verschut, V.; Chakraborty, A.; Rozpędowska, E.; Lebreton, S.; Bengtsson, M.; Flick, G.; Witzgall, P.; Piškur, J. Chemical signaling and insect attraction is a conserved trait in yeasts. Ecol. Evol. 2018, 8, 2962-2974. [CrossRef]

72. Madden, A.A.; Epps, M.J.; Fukami, T.; Irwin, R.E.; Sheppard, J.; Sorger, D.M.; Dunn, R.R. The ecology of insect-yeast relationships and its relevance to human industry. Proc. Biol. Sci. 2018, 285, 20172733. [CrossRef]

73. Aldridge, R.L.; Britch, S.C.; Allan, S.A.; Tsikolia, M.; Calix, L.C.; Bernier, U.R.; Linthicum, K.J. Comparison of volatiles and mosquito capture efficacy for three carbohydrate sources in a yeast-fermentation $\mathrm{CO}_{2}$ generator. J. Am. Mosq. Control. Assoc. 2016, 32, 282-291. [CrossRef] [PubMed]

74. Smallegange, R.C.; Schmied, W.H.; van Roey, K.J.; Verhulst, N.O.; Spitzen, J.; Mukabana, W.R.; Takken, W. Sugar-fermenting yeast as an organic source of carbon dioxide to attract the malaria mosquito Anopheles gambiae. Malar. J. 2010, 9, 292. [CrossRef] [PubMed]

75. Mweresa, C.K.; Omusula, P.; Otieno, B.; Van Loon, J.J.A.; Takken, W.; Mukabana, W.R. Molasses as a source of carbon dioxide for attracting the malaria mosquitoes Anopheles gambiae and Anopheles funestus. Malar. J. 2014, 13, 160. [CrossRef]

76. Sukumaran, D.; Ponmariappan, S.; Sharma, A.K.; Jha, H.K.; Wasu, Y.H.; Sharma, A.K. Application of biogenic carbon dioxide produced by yeast with different carbon sources for attraction of mosquitoes towards adult mosquito traps. Parasitol. Res. 2016, 115, 1453-1462. [CrossRef] [PubMed]

77. Jerry, D.C.T.; Mohammed, T.; Mohammed, A. Yeast-generated $\mathrm{CO}_{2}$ : A convenient source of carbon dioxide for mosquito trapping using the BG-Sentinel ${ }^{\circledR}$ traps. Asian Pac. J. Trop. Biomed. 2017, 7, 896-900. [CrossRef]

78. George, J.; Jenkins, N.E.; Blanford, S.; Thomas, M.B.; Baker, T.C. Malaria mosquitoes attracted by fatal fungus. PLoS ONE 2013, 8, e62632. [CrossRef]

79. Reeves, W.K. Oviposition by Aedes aegypti (Diptera: Culicidae) in relation to conspecific larvae infected with internal symbiotes. J. Vector. Ecol. 2004, 29, 159-163.

80. Geetha, I.; Paily, K.; Padmanaban, V.; Balaraman, K. Oviposition response of the mosquito, Culex quinquefasciatus to the secondary metabolite(s) of the fungus, Trichoderma viride. Memórias do Instituto Oswaldo Cruz 2003, 98, 223-226. [CrossRef]

81. Eneh, L.K.; Saijo, H.; Borg-Karlson, A.-K.; Lindh, J.M.; Rajarao, G.K. Cedrol, a malaria mosquito oviposition attractant is produced by fungi isolated from rhizomes of the grass Cyperus rotundus. Malar. J. 2016, 15, 478. [CrossRef]

82. Lindh, J.M.; Okal, M.N.; Herrera-Varela, M.; Borg-Karlson, A.-K.; Torto, B.; Lindsay, S.W.; Fillinger, U. Discovery of an oviposition attractant for gravid malaria vectors of the Anopheles gambiae species complex. Malar. J. 2015, 14, 119. [CrossRef] 
83. Xia, Y.; Wang, G.; Buscariollo, D.; Pitts, R.J.; Wenger, H.; Zwiebel, L.J. The molecular and cellular basis of olfactory-driven behavior in Anopheles gambiae larvae. Proc. Natl. Acad. Sci. USA 2008, 105, 6433-6438. [CrossRef] [PubMed]

84. Liu, C.; Pitts, R.J.; Bohbot, J.D.; Jones, P.L.; Wang, G.; Zwiebel, L.J. Distinct olfactory signaling mechanisms in the malaria vector mosquito Anopheles gambiae. PLoS Biol. 2010, 8, e1000467. [CrossRef] [PubMed] 